\title{
Inverted Classroom as Innovative International Educational Technology in Teaching Doctors in Global Challenges Era
}

\author{
Krasilnikova Natalja Valerjevna \\ Chair of Pedagogy and Psychology, Postgraduate Eduction \\ Faculty \\ Pavlov First Saint Petersburg State Medical University \\ Saint Petersburg, Russia \\ nataljakrasilnikova@yandex.ru \\ Vanchakova Nina Pavlovna \\ Chair of Pedagogy and Psychology, Postgraduate Education \\ Faculty \\ Pavlov First Saint Petersburg State Medical University \\ Saint Petersburg, Russia \\ nvanchakova@gmail.com
}

\author{
Vatskel Elizaveta Aleksandrovna \\ Chair of Pedagogy and Psychology, Postgraduate Education \\ Faculty \\ Pavlov First Saint Petersburg State Medical University \\ Saint Petersburg, Russia \\ vatskel@mail.ru
}

\author{
Vaucher Paul \\ Unit of Research in Mobility \& Musculoskeletal Care \\ Haute ecole de Sante \\ Fribourg, Switzerland \\ paul.vaucher@hes-so.ch
}

\author{
Bogatyrev Andrei Anatoljevich \\ Chair of foreign language education, Institute of \\ International Education \\ Moscow Pedagogical State University) \\ Moscow, Russia \\ aa.bogatyrev@mpgu.edu
}

\author{
Baraboshina Anna Aleksandrovna \\ Chair of Pedagogy and Psychology, Postgraduate Education \\ Faculty \\ Pavlov First Saint Petersburg State Medical University \\ Saint Petersburg, Russia \\ anna.baraboshina@gmail.com
}

\begin{abstract}
The research is based on the accomplishment experience of The international Swiss-Russian TICOM project Transcultural Inverted Classrooms in Osteopathy and Medicine, focused on testing modern technologies for inverted classes. The investigation is dedicated to the topical issue of upgrading doctors' vocational skills and providing medical vocational training in international context, meeting European Union demands and standards for medical workers. Modern competence-based conception of the vocational education and training integrity leads to distinguishing between hard skills and soft skills of a doctor, having to solve both bodily treatment and interpersonal communication tasks. These two groups of tasks are tightly interconnected in many ways and modes, vehemently influencing the efficiency of medical help in intersubjective and "bio-psycho-social" paradigm. So "medical treatment of the whole patient' has become a point of competitiveness in vocational sphere. The complexity of the task of providing modern patient with proper medical treatment leads logically to introducing of meta-competences level of professional preparedness as a tool of vocational education expertise and designing new approaches and solutions to teaching students medical profession. At the same time new educational content
\end{abstract}

demand new forms and methodology of teaching. The educational task of fostering holistic approach in doctor-topatient communication was tried in Swiss-Russian Inverted Classroom educational and research project, challenging the preparedness of medical students for vocational activity to follow such values as "openness, professional integrity, and warmth". The analysis of effectiveness of the approach, educational form (i.e. Flipped Classroom), educational tools and techniques used is discussed in the report.

Keywords: human capital, global challenges, international careers and international medical education, expertise in education, flipped classroom, ICT, integrity of education and vocational competency of a doctor

\section{INTRODUCTION}

Education is traditionally and justly viewed as an important part of human capital $[1 ; 2 . ; 3]$. The importance of medical care quality both in personal and in social contexts cannot be argued. The problem of medical up-to-date education can be solved by application of modern teaching 
of training and job performance. This tightly connected with employee's responsibility in choosing and taking an educational trajectory and unique personal educational path within the continuous vocational (medical) education system. So building a unique educational path conforms with selfdirected and self-regulated learning. Designing a universal educational module like that one in TICOM project can be viewed as providing a competitive educational supply product for educational demand market.

The key peculiarities of the self-directed learning, well reflected in theory $[14 ; 15 ; 16 ; 17 ; 18 ; 19 ; 20 ; 21]$ in this case can be summed as follows:

- it can happen in a variable educational environment. It can include various activities and sources - reading alone or networking, taking part in the research groups, internship, discussion, brainstorming, dialogue through some digital sources, reflexive dialogue, written works and so on.

The student takes responsibility for planning the decisions connected with the education and learns how to transfer knowledge and skills from one situation to another.

The teacher's role in self-directed learning model is to model the whole lesson system and to provide communication among the students, provide and coordinate the work with the teaching material, assessment of the results, and facilitating critical thinking. In case of healthcare teaching, it helps developing medical judgment.

The self-directed learning system models and regulates team-building and net-working processes and promotes competencies that are necessary for net-working in the multidisciplinary team.

- student's autonomy is formed and the necessary competencies for working with the scientific literature, the skills of searching, collecting, grouping, processing, analyzing the data, developing the medical judgment that are formed are highly required by healthcare specialists.

\section{RESEARCH METHODS AND METHODOLOGY}

\section{A. The inverted classroom technology}

The Inverted Classroom technology allows organizing preconditions for the self-directed learning within the formal education framework. The acquisition of syllabus and competencies is organized the way that each student works under his/her own tempo, using the methods and tools that are common to modern student.

Under this technology, various gadgets (computers, tablet computers, smart phones) and means of communication (in this case Skype, Slack, Google, etc.) can be used. On one hand, it allows the student to polish the skills of working using computer technologies that is needed in contemporary information society. On the other hand, it corresponds the ways of communication that are common for younger generation, thus raising their interest and learning motivation. one's necessary skills. Modern medical job market has produced demand not only for a diploma, but also for certificates of employee's competencies in particular spheres 
The answers were presented to the group as a short report and were loaded into the ActCom system (based on Google Disk);

d) The shift from theory to practice. The groups simulated a 45-minute clinical conversation with the patient;

e) SWOT-analysis of the lesson: analysis, and reflection, determination of the objectives of the subsequent work on this topic, the possibilities of using the knowledge in practice;

f) Receiving themes for further studying and literature for doing the subsequent homework.

Information provided to students was carefully selected by teachers, discussed and approved during joint working meetings. All the information provided to students corresponded to those didactic goals and objectives that were set within the framework of each lesson. Previously, a long and laborious work was carried out to develop the classes and to synchronize them in two countries, taking into account cross-cultural and regional peculiarities, restrictions and even the difference in time zones. Students were registered in all the electronic systems necessary for conducting online classes (Google, Slack, etc.). Materials were sent to each student by email, including personal doctor empathy questionnaires.

The Swiss and Russian groups worked both individually, each with its own moderators (E.A. Vatskel, N.V. Krasilnikova; P. Vaucher, J. Liengme, A. Baraboshina), and jointly, via Skype. The episodes of international communication between the groups of students included greeting, presenting the results of their work, working on a case study within a "clinical vignette" $[21 ; 14]$ (i.e. a clinical conversation with the patient), and following a joint discussion of the lesson SWOT analysis conducted by each side.

The Second Inverted Classroom "Shared decision making" The second inverted classroom highlighted issues of patient-centered communication and joint decision-making, determining the goals of the interaction between the doctor and the patient, the patient's self-management, the formation of constructive strategies for coping behavior in the conditions of the disease. The general lesson schedule was identical to the first one.

The central plot of the lesson was medical consulting a "difficult patient", performed by actor, in fact being oneself an experienced doctor. The patient is to be seen by four physicians - a neurologist, a neurosurgeon, a physical therapist and an osteopath. Their aim is to understand patient's situation, to identify and decide on what needs to be addressed or prioritized when treating patient's situation and pain and to help a patient in the decision-making. Using active communication skills, four volunteer students need to interview the patients to have the patient choose the most appropriate actions to solve the health problems. They are to facilitate patient's choices and address the problem in all its complexity. Other students can provide cues, tips and suggestions using Slack and the guidelines related to the topic

Students need to show signs of openness, professional integrity, and warmth. They have to find clues to the patient's thoughts and feelings and identify the state and situation of the patient correctly. As they move forward, they need to make 
The applied tasks in the second Inverted Classrooms were sense of the situation and build a clear picture of the problem. They need to be present, focused, and engaged in building an accurate picture of patient's state of mind and facilitate patient's choices for medical treatment.

If the students are able to build trust and confidence, the patient will reveal certain necessary information. The final goal of the interaction is that within the time frame, the interviewer can work out a clear strategy on priorities in medical treatment and what is to be done by the patient before the next appointment.

\section{Moderation of Inverted Classroom}

The international Inverted Classroom was based on complex and flexible system of control and moderation of purposeful learning process. Moderation of inverted classroom has been designed as a multi-layer system of leading, monitoring and regulating the learners' educational activity process. Students' vocational self-management skills were stimulated by expert opinion of fellow-students within a team (so called "Quartet"), by accessible supportive instructional materials, by teachers as moderators' opinion, by the actor oneself, playing the role of 'difficult patient', and by international experts board.

\section{E. The international collaboration component}

The international collaboration within working under the Inverted Classroom models can help to build a common educational space, to promote the exchange of experience, to provide new approaches to communication in vocational context. It helps to identify, define, interpret and critically assess ethic values and to enrich the collaborating countries with local approaches.

The conditions for international Inverted Classroom were partly overlapping with those, pertaining to Communicative Quest, implying "learning not only vocabulary and grammar, but also social skills, foreign communicative culture, sensitivity to style as well as sense of appropriateness of communicative move in certain communicative situation" [24, p. 121]. However, the substantial role belonged to finding personal approaches to reaching the key goals of medical educational meta-competence in conversation with a "difficult patient" within doctor's vocational culture framework, established in such terms as "be present, focused and stay engaged with your patient". This difficult kind of doctor-to patient communication sometimes reaches the fifth (i.e. the highest) level of interpersonal communicative interaction goal-setting, labelled as "revalorization and change of pre-set values of the interlocutors" [cf. 25].

\section{RESULTS}

The two Inverted Classrooms produced personal awareness effect on the students. They processed the educational information and changed their primary attitudes to the issue of doctor-to-patient communication. Task-based roleplaying stipulated application of various vocational knowledges and skills, added a personal touch to new knowledges, triggered medical students' interest for designing strategies for communicating with and treating a "difficult patient". challenging, appealing to students' vocational metacompetence, provoking actions, reflections and discussions. Students received a most valuable message for their possible integration into world standard of professionalism - "be present, focused and engaged with your patient".

After conducting two Inverted Classrooms, the students were interviewed in an unrestricted format about their impressions and discoveries in the lessons.

Here below are the student's Inverted Classroom project assessment four top by popularity results:

1. The proven ability to communicate with foreign colleagues, to learn cooperatively and to have the exchange of the experience.

2. The activity and personal performance that they can show in the search and processing of relevant information;

3. The opportunity to try being a "real" doctor when communicating with the virtual (simulated by the actor) patient.

4. The productive application of familiar and previously unfamiliar study methods and electronic tools (laptops, smart phones, tablet computers) as well as remote communication and interaction technologies.

The main discovery statement of the students made was as follows: "The real patient can be very difficult to interact with. Real life communication with the patient is far from those "ideal images" the students had before. The real-life patient's peculiarities can leave an imprint the clinical conversation and, ceteris paribus, even interfere destructively with diagnosis process". This implies learning or designing special strategies for establishing/building a reliable interpersonal contact with the patient and organizing necessary exchange of appropriate vocationally significant reliable and useful information.

The students' feedback and assessment was very positive. Many students found Inverted Classroom an effective and useful tool for vocational education and revalorization of their learner's attitude. One of indirect results was also an observable increase in interest in English and special vocational publications in English.

\section{DISCUSSION}

Inverted classroom technology implies a change in the teacher's role. The teacher cooperates with students in the process of their learning, there appears a joint contribution to the learning process. The inverted model places great responsibility for learning on the students, giving them an incentive for genuine professional development. Educational activities can be led and controlled by students, and communication between students can become a propelling power of the process.

\section{A. Monitoring the educational activity proved fruitful}

A positive impact was made by the pre-organization - the students were divided into micro-groups in advance, all the instructions were given to them in advance, there was a clear 
vocational education and training as one of great importance [cf. 26; 27] but it was not explored partly due to universalist approach, realized in the project TICOM.

\section{CONCLUSION}

As it was stated earlier the project TICOM was aimed at the elaboration, creation and testing of a specially designed educative package for the common frame of vocational training of universal doctors' and medical staff patient-centred communicative skills and meta-competencies. The ability of the educational package for forming such skills have been confirmed successfully. The proposed by the participants of the project "educative package" due to its universalism and the use of advanced classroom technologies (modern educational technologies), in particular, informational ones, can be used by various organizations that are involved into healthcare education. It is assumed valuable not only in doctors training but also medical stuff and non-physical health professionals training. Target organizations include medical universities, medical colleges, various organisations, for example, "The Red Cross" and the others.

Experimentation with conducting Swiss-Russian Inverted Classroom proved fruitful in attaining such groups of targets as:

a) Application of modern technologies to teaching medical students internationally;

b) Providing interdisciplinary interconnectedness and integrity of final educational outcomes

c) Uncovering axiological meta- disciplinary components of professional medical training;

d) Developing interactive teaching methodology for vocational doctor-to-patient interaction training;

e) Developing learning to learn component in modern tasksolving vocational training;

f) Developing self-directed learners' attitude and readiness;

g) Developing learners' readiness for international lifelong learning;

h) Developing international students' vocational medical soft skills in English;

i) Developing Russian medical students human capital internationally;

On a macro-level the experimentation may be viewed as part of such educational global processes as:

a) Globalization and internationalization of education.

b) Developing integrate approach to educational medical training, based on the idea of treating the whole patient.

c) Teaching profession within frame of Inter-subjective, Inter-personal and International communicative paradigm.

d) Establishing direct connections between various medical educational centers on planet Earth.

e) Opening new opportunities of life-long learning and vocationalization of educational outcomes. 
[9] NO. P. Vanchakova, NO. V. Krasilnikova, E. A.Vatskel, R. Andorno, A. M. Elsner, and A. P. Chernyavskaya, "Perception of the patient as a person: Medical humanities", Saint Petersburg, Publishing house "Chelovek", 2019, 208 p.

[10] P. Ranjan, A. Kumari, and A. Chakrawarty, "How can doctors improve their Communication skills? ", Journal of Clinical and Diagnostic Research, 2015, vol. 9 (3), JE01-JE04.

[11] M. J. Hashim, "Patient-centered communication: basic skills", American Family Physiciano, 2017, vol. 95, no. 1, pp. 29-34.

[12] W. Branch, "Treating the whole patient: Passing time-honoured skills for building doctor-patient relationships on to generations of doctors", Medical educationo, 2014, 48, pp. 67-74. DOI: 10.1111/medu.12369.

[13] C. W. Van Staden, "The conceptualization of "soft skills" among medical students before and after curriculum reform", African Journal of Psychiatry, 2006, no. 9 (1), pp. 33-37.

[14] C. Freeman and NO. A. Schiller, "Case studies and flipped classroom", Journal of college science and teaching, 2013, vol. 42, no. 5, pp. 62-66.

[15] J. O'Flaherty and C. Phillips, "The use of flipped classrooms in higher education: A scoping review", The Internet and Higher Education, 2015, vol. 25, pp. 85-95.

[16] L. Abeysekera and P. Dawson, "Motivation and cognitive load in the flipped classroom: definition, rationale and a call for research", Higher education research and development, 2015, vol. 34, no. 1, pp. 1-14.

[17] M. T. Villalba, G. Castilla, and S. Recondo-Duarte, "Factors with influence on the adoption of the flipped classroom", Journal of information technology Education: Research 2018, vol. 17, pp. 441-469.

[18] NO. Edwards, "An analysis of the Characteristics of self-directed learners and strategies to enhance self-directed learning in education systems: transcending boundaries", Official Proceedings of the Asian Conference on Education, 2015 [Electronic resource]. Available at: https://pdfs.semanticscholar.org/3496/5f915f380bf70a43a0f85308b330a b4e9afa.pdf (Accessed: 10 October 2019).

[19] S. G. Ceylaner and F. Karakus, "Effects of the flipped classroom model on student's self-directed learning readiness and attitudes towards English course", English Language Teaching, 2018, vol. 11, no. 9, pp. 129-143.

[20] Q. Liu, W. Peng, F. Zhang, R. Hu, and Y. Li, "The effectiveness of Blended Learning in health professions: Systematic Review and MetaAnalyses", Journal of Medical Internet Research, 2016, vol. 18(1): e.2.

[21] S. Arnold-Garza, "The flipped classroom teaching model and its use for information and literacy instruction", Communication in information literacy, 2014, vol. 8, issue 1, pp. 8-22.

[22] K. Jeyashree and K. P. Binod, "Case vignette: a promising compliment to clinical case presentations in teaching", Education for health change in learning and practice, 2013, 26 (1), pp. 21-24

[23] T. P Young, C. J. Bailey, M. Guptill, A. W. Thorp and T. L. Thomas, "The Flipped Classroom: A Modality for Mixed Asynchronous and Synchronous Learning in a Residency Program", West Journal of Emergency Medicine, November, 2014, 15 (7), pp. 938-944.

[24] A. V. Tikhomirova, A. A. Bogatyrev, and O. P. Bogatyreva, "Communicative Quest as an innovative EFL teaching technology", Modern Journal of Language Teaching Methods, June 2018, vol. 8, issue 6, pp. 147-158. DOI: 10.26655/mjltm.2018.6.5.

[25] A. A. Bogatyrev, A. AV. Tikhomirova, and O. P. Bogatyreva, "Interactivity levels of pedagogic presentation text information", World of linguistics and communication: electronic scientific journal. 2017, 1, pp. 45-58 [Electronic resource]. Available at: www.tverlingua.ru (Accessed: 10 October 2019).

[26] M. Prosen, "Introducing transcultural nursing education: Implementation of transcultural nursing in the postgraduate nursing curriculum", Procedia. Social and behavioral Sciences, 2015, vol. 174, pp. 149-155.

[27] M. Teräs, "Cultural Diversity and Vocational Education and Training", In: in Handbook of Vocational Education and Training, Springer, Cham, 2019. 